\title{
The Study on the Effect of the Piston Shapes through Biodiesel Mixture Combustion in Diesel Engine
}

\author{
Changchun $\mathrm{Xu}^{1}$, Md. Abul $\mathrm{Kalam}^{2}$, HaengMuk $\mathrm{Cho}^{3, *}$ \\ ${ }^{1.3}$ Division of Mechanical and Automotive Engineering, Kongju National University 1223-24, Cheonan Daero, Seobuk-gu, Cheonan-si, \\ Chungcheongnam-do 331-717, South Korea. \\ ${ }^{2}$ Department of Mechanical Engineering, University of Malaya.
}

\begin{abstract}
In this work, we studied the combustion characteristics of a direct injection compression ignition (DICI) engine. Diesel uses different cylinder geometry and different injection rate shapes. We can change the piston surface to compare turbulent flow energy and eddy viscosity. So we use three geometric piston bowls for comparison. The geometry is set to a single circle, a double circle and a flat bottom so that the engine combustion characteristics can be improved and the exhaust emissions can be reduced. Therefore, we can find through simulation that a double circular geometry piston with a better geometry has the highest turbulent kinetic energy (TKE) and this results in two peak heat releases with a main peak heat release during premixed combustion. And secondary peak heat release occurs during the mixed controlled combustion phase. This article adopts this geometry. The air-biofuel mixture can be squeezed in two wheels because better vortexing can squeeze the mixture better to improve the mixture. Therefore, this article will examine the bowl-shaped geometries that produce high-KTE and low-viscosity fuels, single-circle geometries, double-circular geometries, and flat base geometries. In general, we can increase the air/fuel ratio by changing the geometry to reduce exhaust emissions.
\end{abstract}

\section{Introduction}

In the engine, we can use various methods to control the exhaust emission. On the whole, there are two methods to improve engine performance, one is changing the engine structure, another changes the fuel like as biofuel combustion in the engine chamber, like improve combustion chamber design for changing the air-fuel mixture ratio, and in the exhaust system the EGR used also can change the exhaust production. Or through change the injector's angle can improve the air-fuel mixture. And another method can make the alternate fuel to use for engine performance, due to diesel and gasoline is fossil fuel, as if going on using these fossil fuels can pullet the environment. In addition, to change engine structure there are change the burning fuel for improving the engine performance, the burning fuel can be used like as biofuel, life refuse oil, plant seed oil, after the addition of aromatic agents, product fuel for the engine using. In this paper, just like changing the fuel for engine last thought, we will consider the shape of the engine piston surface about with a fuel-air degree of mixing. In general, the mixture of the air-fuel is important for the engine, so in the paper, the author will research the effect of the different shapes of the piston in the cylinder improve the mixture of the air-fuel coefficient. Through changing the shape of the piston surface, the better shape for the engine was found, because the pre-mix of the air- fuel is very important for the engine, so just making the air-fuel to mix better in the premixing process (induction stroke). And then paving the way for the combustion after.

\section{Research background}

It is interesting to investigate the use of biodiesel in the diesel engine, aiming to increase the efficiency of operations and to reduce the emissions of pollutants. And The performance and emission characteristics of a CI (compression ignition) engine depend primarily on the combustion process. The combustion of the fuel in the cylinder depends in turn on various factors such as fuel injection timing, fuel injection pressure, engine design such as combustion chamber shape and injector position, fuel properties, number and size of injection holes, fuel injection mode, air Whirlpool, fuel injection, etc. the researcher in order to improve the engine combustion to make good premix when the air and fuel injected into cylinder through changing the piston surface geomerty for improving the combustion characteristics and promote the air-fuel mixture during the piston move down and compression stroke. The shape of the combustion chamber and the fluid dynamics inside the chamber are important in diesel combustion process. As the piston moves upwards, the gas is pushed

\footnotetext{
* Corresponding author: hmcho@kongju.ac.kr
} 
into the piston bowl. The geometry of the piston bowl can be designed to produce squish and swirling action which can improve the air/fuel mix turn formation before ignition takes place (premix). And when the piston moves down, due to the different shapes of the surface also can affect the combustion of the air and biofuel. Context above the combustion and emission formation processes in diesel engines have a close relationship with the piston bowl geometry which can strongly affect the air fuel mixing before the combustion starts that is premixing. And recently, a few experimental studies on the effects of different bowl geometries of diesel engines fueled with biodiesel have been carried out. Jaichandar an Annamalai studied the influence of bowl geometry on the engine performance in a diesel engine fueled with biodiesel[18,21]. And in their study, Four bowl geometries, namely $\mathrm{HCC}($ Hemispherical Combustion Chamber), FCC(Flat Combustion Chamber) and DHCC(Double Hemispherical Combustion Chamber), IBCC(Inclined Bottom Combustion Chamber) were investigated. And Dolak and Reitz optimized the bowl geometry of a light-duty diesel engine using a two spray angle nozzle by considering variables such as the start of injection, the fractional amount of fuel per injection and the swirl ratio[19]. Raj et al. conducted study concerning energy efficient piston configuration for effective air motion, wherein four configurations namely flat, inclined, center bowl, and inclined offset bowl pistons were investigated[20]. So the paper main goals desired from the design of chamber geometry are to optimize the mixing of the fuel and air before during ignition and to improve the flow of the exhaust products once combustion is complete. Then in this paper, the researcher sets the engine piston geometry as Figure 1.

Previously there were many researchers have investigated related to the throttle body effects with engine intake system and related to the piston shapes and cylinder geometries effects about the engine. In these researches, the researchers change the throttle bodies' shapes or change the center of the throttle valve for varying the airflow velocity and make the airflow smooth into cylinder. In addition, some researchers have changed the cylinder volume or changed the geometry of the piston surface, or added some components to change the airflow direction. For example, we can change the direction of the air flow by adding a slice to allow air to enter the cylinder and create a lot of gas with a higher swirl viscosity, so that the air and fuel are completely mixed.

As experimental work requires a lot of money and human power, researchers turned their attention towards the theoretical prediction for the optimization techniques. Researchers such as Mobasheri and Peng [1] studied the effect of Re-entrant combustion geometry in Computational Fluid Dynamics (CFD) in a high speed diesel engine(HSDI). And these researchers reported that combustion bowl parameters had a huge effect on the emission and performance characteristics, among which lowering the bowl depth resulted in higher $\mathrm{NO}_{\mathrm{X}}$ emission. And other research workers such as Raj et al.[3] reported the air motion for four different geometries for a single cylinder diesel engine, reasoned out that combustion bowl profile played a key role in incylinder air fuel mixing. And researcher Kidoguchi and Yang [5] stated that combustion bowl with lower throat diameter and higher squish magnitude results in simultaneous reduction of particulate matters and oxides of nitrogen which are harmful to the environment and human health. And another investigator Subramanian et al.[9] optimized the combustion chamber using CFD for a diesel engine with mono cylinder. The researchers concluded that turbulent kinetic energy and swirl ratio profile had a huge impact on the combustion bowl profiles. The researcher Lin et al.[8] examined the performance and in cylinder air gesture for three different combustion chamber geometries for a diesel engine used in agricultural land. The author optimizes the bowl parameter by studying the influence of turbulence, finds the cylinder's optimized geometry, increases turbulent viscosity and improves turbulent kinetic energy, improves air-fuel mixing, combustion and diffusion stages, uses minimal fuel consumption and reduces nitrogen oxides and smoke emissions. Researchers, Gafoor and Gupta[14] reported numerical examine on various swirl ratios on the piston swirl had a great effect on the cylinder pressure and emission behavior with high bore to bowl ratio. In these researchers reasoned out that enhancement in turbulence would have an effect on fuel consumption, soot, and $\mathrm{NO}_{\mathrm{x}}$ emission. Prasad et al.[13] found the consequence of various re-entrant bowl produced better swirl and turbulent kinetic energy and reduced $\mathrm{NO}_{\mathrm{x}}$ and soot emission levels. Zhu et al.[15] tested the combustion performance and emission behaviors of various piston bowl parameters. With these results, we can find that increase of the toroidal radius, and with this effect get better combustion efficiency and higher reduction of soot emission. The re-entrant combustion geometry was preferable to direct injection diesel engine owing to its higher cylinder pressure and better soot reduction process and reported by other researchers. A lot of researchers investigated on the field of optimization of the combustion bowl, mainly on the re-entrant design with respect to the fuel, load, and speed conditions. Using this re-entrant bowl, the engine can reduce the emission and soot particular.

In the context, due to the fossil energy source and the production after combustion, some researchers carried out with some various combustion bowl geometries with the alternative energy sources using theoretical and experiments. Li et al. [7] carried out the impact of piston bowl geometry use CFD tool and the fuel using biodiesel-powered diesel engine with three different combustion bowls, and the name of three bowls are Hemispherical, Shallow depth, and Omega Combustion cylinder with the same cylinder. This research can be found the Omega Combustion chamber got high-speed engines owing to superior squish motion, and the 
geometry of piston made the fuel and air complete mixture cause the engine performance improvement. And Ramesh Bapu et al.[16] probed the consequence of a modified combustion bowl profile on a diesel engine powered by Calophylluminophyllum methyl ester. This investigation can be found that the bowl with the lower diameter to depth ratio would have superior squish flow resulting in the enhancement of the performance characteristics. Jaichandar and Annamalai[12] experimentally studied the toroidal and shallow depth reentrant combustion bowl using pongamia biodiesel to power a diesel engine. So they found the reentrant bowls tended to improve the mixture formation by better fuel and air interaction resulting in the improvement of the performance characteristics. And another researcher Wamankar and Murugan[6] experimentally analyzed the effect of internal jet induced piston bowl with emulsified diesel fuel. The researcher uses this piston bowl achieved a superior emission reduction through the modified piston bowl because swirl variation and fuel-air interaction. About above of paper, we can found main goal that combustion bowl profile modification can be utilized for the improvement of performance and emission behavior of diesel and biodiesel fuels.

Against this background, we can found various researches for discovering the effect of the engine cylinder and piston geometry. This geometry of piston bowl on the various performance, combustion and emission factors but still many factors can affect the air and fuel mixture like the throttle body. In this paper the reseacher in order to investigates the effect of geometry of the piston for the engine performance, so does some simulations for this assumption.

\section{Structural models}

Before analyzing engine performance and emissions, we can set up the model to use the ANSYS program, and in this program, in this study, a dual-valve, four-stroke engine with direct intake and exhaust gas, the manifold has been considered for CFD analysis. A schematic diagram of the engine with the flat piston is as shown in Figure 1. And the specifications of the engine are shown in Table 1. So in this progress, we set the CAD referring to crank angle degree. And we use ANSYS program to create the model of the engine and meshing of it is done by this software. So these Polyhedral trimmed cells have been used for meshing the engine geometry. The plan and elevation of a computational grid of the fluid domain considered are as shown in Figure 2. And in this model, the grid can be set to a better simulation to show that it is set to $3 \mathrm{~mm}$ as the size of the element, and the part of the valve is expressed by setting the grid to 5 because this is partly due to the airflow through the valve Some vortices and valves can prevent air and fuel from passing through, so set the boundary grid to show the effect during the simulation. Due to the combustion process, the air-fuel needs to be better mixed and burned during mixing. Only sufficient mixing of fuel and air can cause sufficient combustion. Therefore, the shape of the piston also plays a role in the combustion process. The authors simulated the effects of different shaped surfaces under simulated combustion conditions.

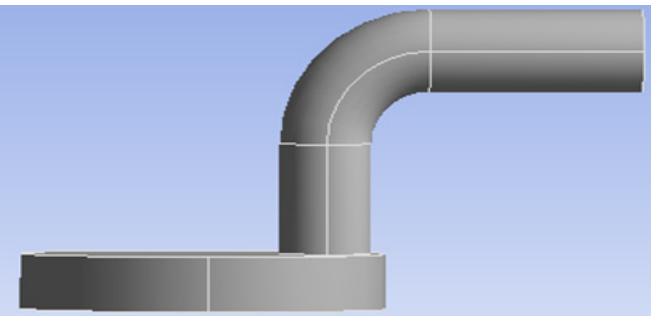

Fig.1. Schematic diagram of the engine with flat piston

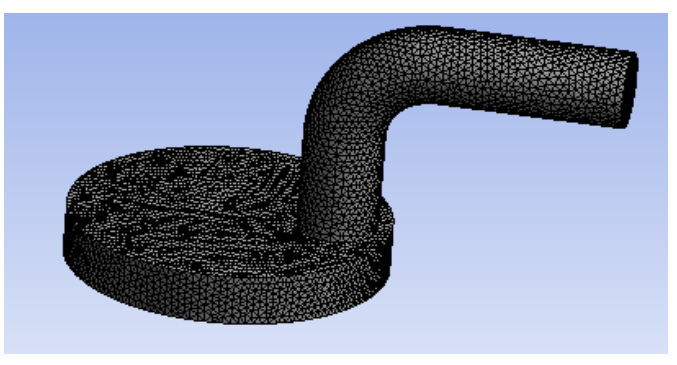

Fig.2. Meshing of the flat piston

And the engine description is shown below

Table 1. The specification of the model

\begin{tabular}{|c|c|}
\hline Type & $\begin{array}{c}\text { Single cylinder, vertical diesel } \\
\text { engine, two-valve, four-stroke } \\
\text { engine }\end{array}$ \\
\hline Bore & $87.5 \mathrm{~mm}$ \\
\hline Stroke & $110 \mathrm{~mm}$ \\
\hline Compression ratio & $10: 1$ \\
\hline Speed & $1500 \mathrm{rev} / \mathrm{min}$ \\
\hline $\begin{array}{c}\text { Maximum intake } \\
\text { valve lift }\end{array}$ & $7.9 \mathrm{~mm}$ \\
\hline IVO: 4.5 CAD bTDC & EVO: $35 \mathrm{CAD}$ bBDC \\
\hline IVC: 35 CAD aBDC & EVC: 4.5 CAD aTDC \\
\hline
\end{tabular}

\section{Model analysis}

In this study, the researchers set up pistons of different shapes. When air and fuel flow into the chamber during this process, the engine with a constant engine speed compares PIV (particle image velocimetry) with different shapes. Finally, the researchers set a constant value setting simulation process and compared the performance of the engine by simulation. And in the different shape, we can observe the different piston shapes produced different levels of TR (tumble ratio) and TKE (turbulent kinetic energy). As shown the phenomenon in below figures. And when during compression stroke, the piston upward TDC (top dead center) due to the high pressure the injector make the fuel inject into the piston surface as tiny droplets with high pressure, with the higher pressure inside of cylinder 
cause air-fuel mixed combustion. In this step, we compare the different shapes of the piston surface's effects, because in this step, the geometry of the surface plays an important role to affect the air-fuel mixture.

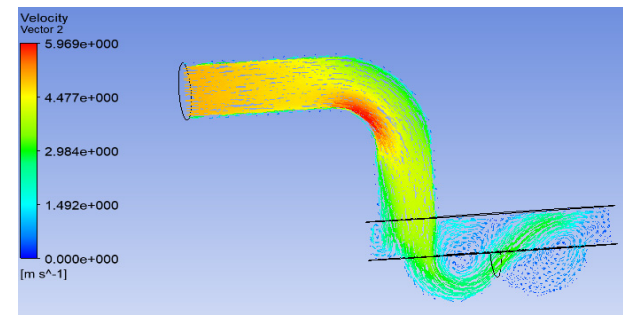

(a)

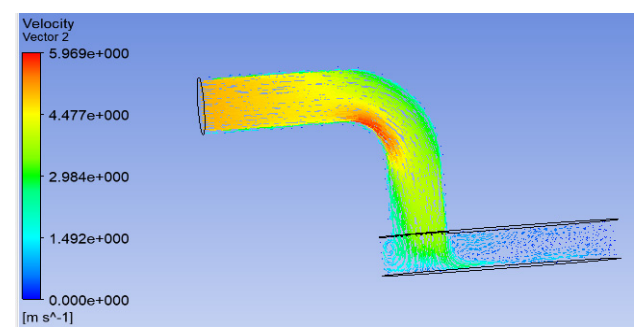

(b)

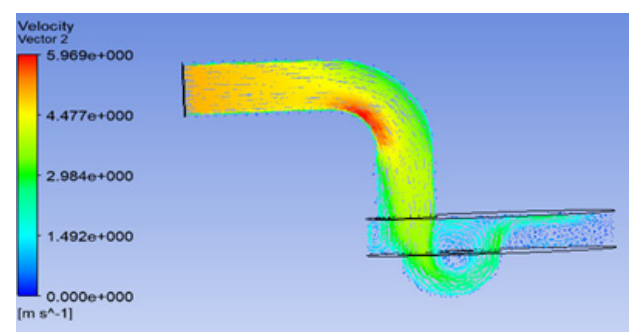

(c)

Fig.3. Velocity of different piston shapes

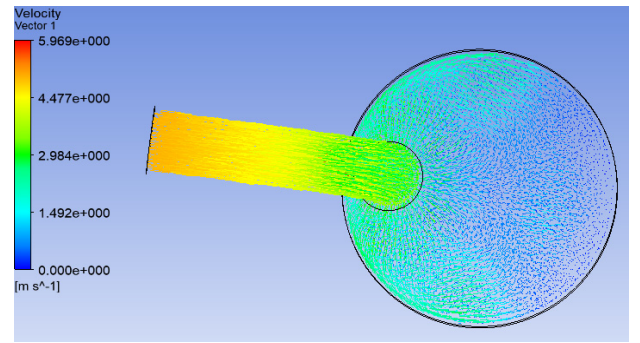

(a)

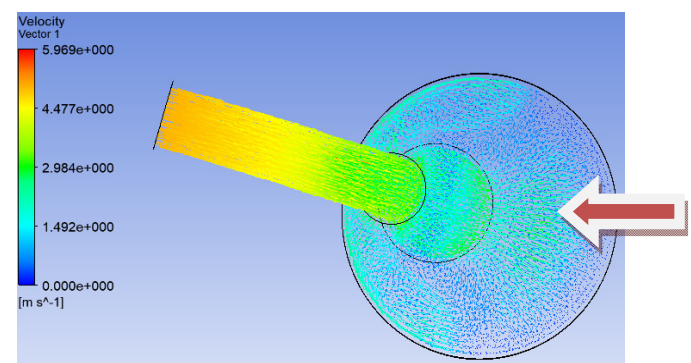

(b)

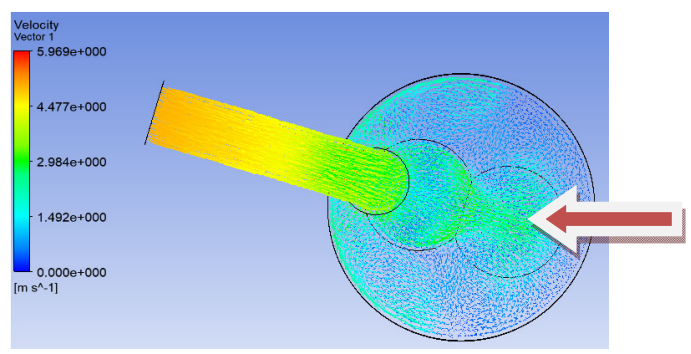

(c)

Fig. 4. Cross-sectional speeds of differently shaped pistons

By the flow rate of the fluid produced by the vertical cutting shown in Figure 3, it can be found that different shapes of piston surfaces can generate different flow rates. Because of the different shapes, it also plays a role in the mixing of air and fuel. Because of the difference in flow velocity, eddy currents can be formed. In space, eddy currents play an important role in the mixing of air and fuel. As shown in the figure, under the influence of eddy currents, the pre-combustion air under compression is compressed. It promoted the mixing with fuel and provided great help for burning. This can be called premixing here. As the phenomenon can be seen in Figure 3, the dual circular surface is more suitable for use. Figure 4 shows the different flow velocities and vortices generated by the piston surface of different shapes under cross-sectional conditions. It can be fully seen from this graph that the area of the vortex generated by the double circular shape is larger than that produced by the single circular shape, however, there is also a slight eddy current generated at the bottom of the piston. Because of a large number of eddy currents, it has a good influence on the mixing of air and fuel, and it directly affects the combustion of the engine and the emission of exhaust gas.

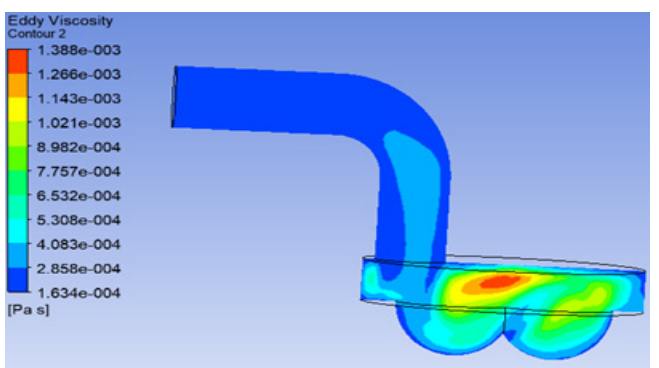

(a)

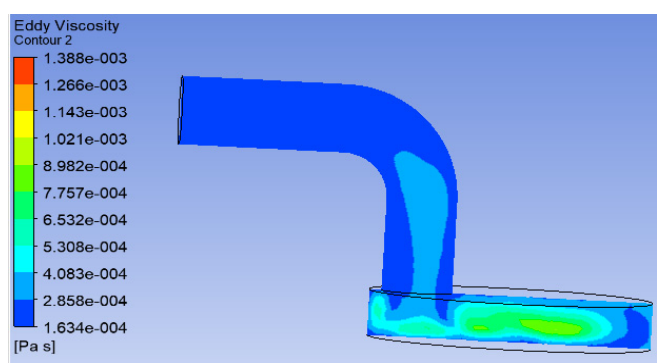

(b) 


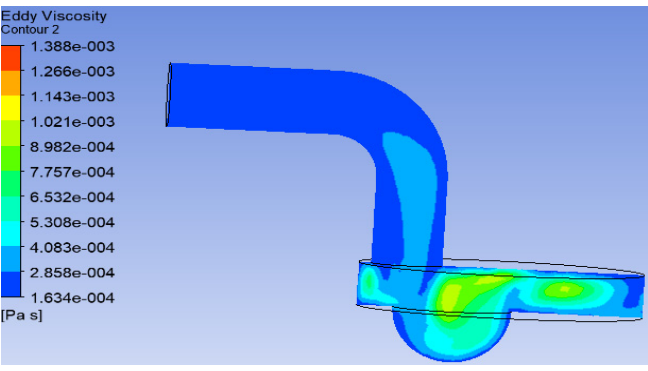

(c)

Fig.5. Eddy viscosity showed through different shapes

In the combustion process, a large amount of turbulences are required to promote the mixing of air and fuel, thereby the geometry can provide complete combustion. In determining the formation of eddy currents, we can determine the intensity of eddy currents based on the magnitude of the eddy viscosity. The mutual influence between two eddy currents is called eddy viscosity. In general, eddy currents are generated along with squish and pressure flow. The generation of these phenomena promotes combustion and reduce emissions of harmful substances. As shown in Figure 5, we can easily find that the double circle is more viscous than the single circle and even more turbulent than the flat bottom. It can be found in the red part of the figure.

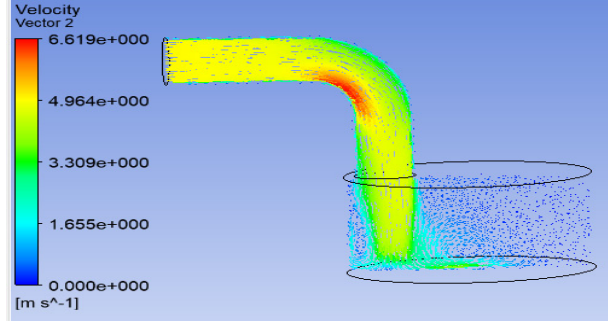

(a)

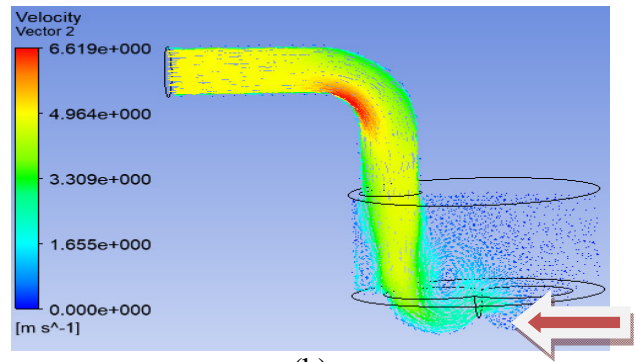

(b)

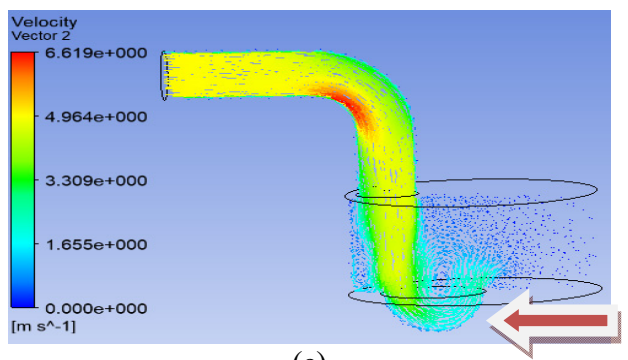

(c)

Fig.6. Different shapes of velocity phenomena during combustion

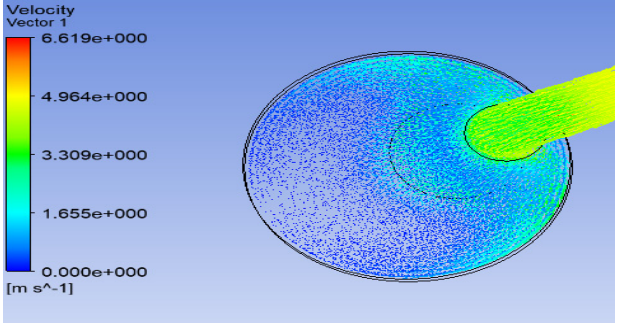

(a)

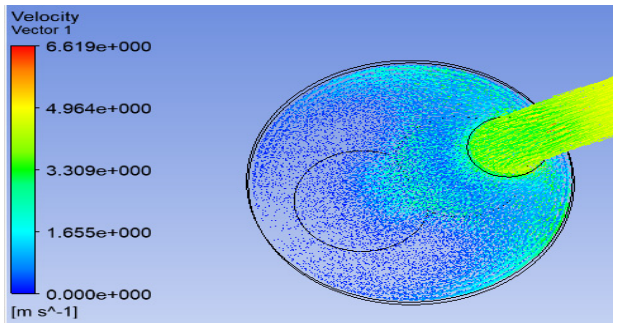

(b)

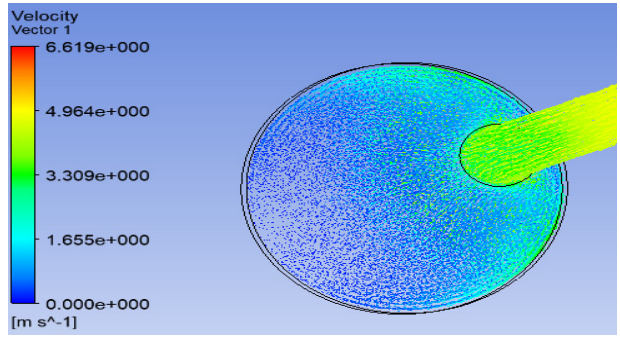

(c)

Fig.7. Cross-sectional speeds of differently shaped pistons during combustion

During the combustion process, the pressure decreases due to the increase of the internal volume of cylinder, but due to a large amount of heat generated during the combustion process, the disadvantages of pressure reduction are compensated. Therefore, the piston during the start of combustion from top dead center to bottom dead center, in order to promote the further combustion of the fuel, the fuel and air need to be fully mixed during the piston move process (combustion process) to avoid the occurrence of incomplete combustion. In turn, the eddy currents mentioned above are connected. As we all know, the combination of different speeds inevitably causes the generation of eddy currents. It can be seen from the figure (indicated by arrows) that the double circle shape has a certain effect on the mixing of the fuel. In the combustion process, not only the vertical direction but also the vortex can be generated in the plane direction, which further promotes fuel mixing and combustion. Just liking the vortex viscosity is shown in Figure 8. Through these comparisons and simulations, we can get an improvement on the shape of the piston, which can further promote the completeness of combustion. This article is only a one-sided discussion of the impact of shape on biodiesel engines. The next step is to further explore the effects of different shapes of piston shapes on the exhaust gas and reduce environmental pollution. 


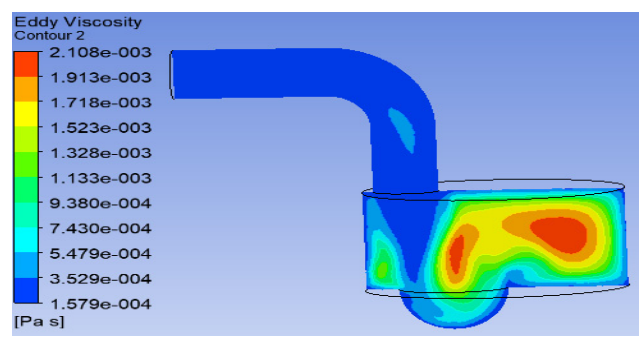

(a)

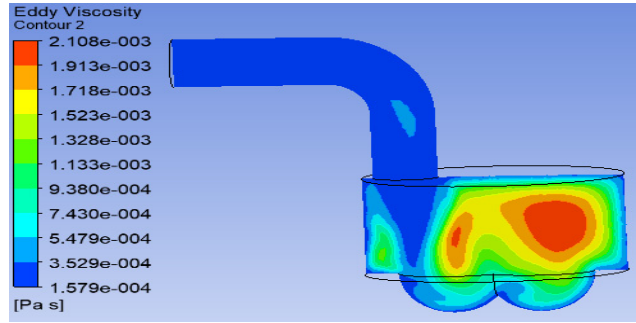

(b)

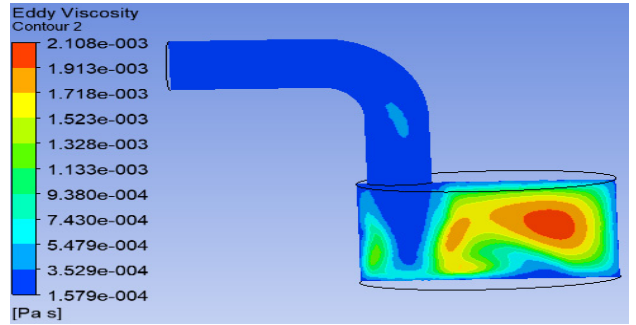

(c)

Fig.8. Eddy viscosity showed through different shapes during combustion

\section{Conclusions}

In this paper, it briefly discusses the pre-combustion and combustion process, the impact of different piston surfaces on the combustion, so as to find the piston shape suitable for engine combustion. By comparing flow velocities, turbulent viscosities, etc., find their respective effects.

In the comparison of the flow velocity, it was found that the shape of the bottom of the double circle was greater than that of the single circle shape. It can better promote the mixing of air and fuel, thereby reducing exhaust emissions.

During the combustion process, we can find that the shape of the double round bottom is more effective than the other shapes in promoting the mixing of air and fuel by comparing Fig. 6,7 , and 8 . In this process, the eddy currents not only can be found in the vertical direction but also can be found in the plane direction.

\section{Acknowledgement}

This work was supported under the framework of international cooperation program managed by the National Research Foundation of Korea (NRF2017K2A9A1A01092911).

\section{References}

1. Raouf Mobasheri, Zhijun Peng, CFD investigation of the effects of re-entrant combustion chamber geometry in a HSDI diesel engine, Int. Scholarly Sci. Res. Innovation 7(4)(2013)770-780.

2. B. Dhinesh, M. Annamalai, Isaac JoshuaRamesh Lalvani, K. Annamalai. Studies on the influence of combustion bowl modification for the operation of Cymbopogon flexuosus biofuel based diesel blends in a DI diesel engine. Applied Thermal Engineering, 112(2017) 627-637.

3. Antony Raj Gnana Sagaya Raj, Jawali Maharudrappa Mallikarjuna, Venkitachalam Ganesan, Energy efficient piston configuration for effective air motion- a CFD study, Appl. Energy 102(2013) 347-354.

4. Hyun Kyu Suh, Chang Sik Lee, A review on atomization and exhaust emissions of a biodieselfueled compression ignition engine, Renew. Sustain. Energy Rev. 58(2016) 1601-1620.

5. Y. Kidoguchi, C. Yang, Effect of high squich combustion chamber on simultaneous reduction of $\mathrm{NO}_{\mathrm{x}}$ and particylate from a direct-injection diesel engine, SAE Technical paper( No. 1999-01-1502), 1999.

6. Arun Kumar Wamankar, S. Murugan, Combustion, performance and emission characteristics of a diesel engine with internal jet piston using carbon blackwater-diesel emulsion, Energy 91(2015)1030-1037.

7. J. Li, W. M. Yang, H. An, A. Maghbouli, S.K. Chou, Effect of piston bowl geometry on combustion and emission characteristics of biodiesel fueled diesel engines, Fuel 120(2014) 66-73.

8. L. Lin, D. Shulin, X. Jin, W. Jinxiang, et al. Effects of Combustion Chamber Geometry on In-Cylinder Air Motion and Performance in DI Diesel Engine, SAE Technical Paper 2000-01-0510, 2000,

9. S. Subramanian, B. Rathinam, J. Lalvani, K. Annamalai, Piston Bowl Optimization for Single Cylinder Diesel Engine Using CFD, SAE Technical Paper 2016-28-0107.

10. Bang-Quan He, Advances in emission characteristics of diesel engines using different biodiesel fuels, Renew. Sustain. Energy Rev. 60(2016) 570-586.

11. V. Ganesan, Internal Combustion Engines, McGraw-Hill, 1996.

12. S. Jaichandar, K. Annamalai, Effects of open combustion chamber geometries om the performance of Pongamia biodiesel in a DI diesel engine, Fuel 98 (2012)272-279.

13. B.V.V.S.U. Prasad, C.S. Sharma, T.N.C. Anand, R.V. Ravikrishna, High swirl-inducing piston bowls in small diesel engines for emission reduction, Appl. Energy 88 (2011) 2355-2367. 
14. C.P. Abdul Gafoor, Rajesh Gupta, Numerical investigation of piston bowl geometry and swirl ratio on emission from diesel engines, Energy Convers. Manage.101 (2015) 541-551.

15. Y. Zhu, H. Zhao, D.A. Melas, N, Ladommatos, Computational study of the effects of the geometry of piston 1 pip for a high-speed direct-injection diesel engine, Proc.IMechE, Part D: J. Automobile Eng. 218 (2004) 875-890.

16. B.R. Ramesh Bapu, L. Saravanakumar, B. Durga Prasad, Effects of combustion chamber geometry om combustion characteristics of a DI diesel engine fueled with calophylluminophyllum methyl ester, J. Energy Inst, (2015) 1-19.

17. H. Sushma, Jagadeesha. K. B, CFD modeling of the in-cylinder flow in Direct-injection Diesel engine, International Journal of Scientific and Research Publications, Volume3, Issue12, December 2013 ISSN 2250-3153.

18. Jaichandar S, Annamalai K. Influences of re-entrant combustion chamber geometry on the performance of Pongamia biodiesel in a DI diesel engine. Energy 2012; 44: 633-40.

19. Dolak J, Reitz R. Optimization of the piston geometry of a diesel engine using a two-spary-angle nozzle. Proc inst Mech Eng Pt D J Automobile Eng2011; 225:406-21.

20. Raj A, Mallikarjuna JM, Ganesan V. Energy efficient piston configuration for effective air motion- A CFD study. Appl Energy 2013; 102: 34754.

21. Jaichandar S, Annamalai K. Effects of open combustion chamber geometries on the performance of pongamia biodiesel in a DI diesel engine. Fuel 2012;98:272-9.

22. Dinech Kumar Soni, Rajesh Gupta. Numerical analysis of flow dynamics for two piston bowl designs at different spray angles. Journal of Cleaner Production 2017; 149: 723-734. 